\title{
RELIABILITY OF THERMAL STRESS IN TAPERING CIRCULAR BARS
}

\author{
Amit Rakshit \\ Department of Mechanical Engineering, \\ Kanad Institute of Engineering and Management, \\ Mankar, W.B, India
}

\begin{abstract}
In this particular article, we have to determine the reliability of thermal stresses in tapering circular bars whose body may be enlarge or indenture due to some raise or fall in the temperature of the body according to the addition. The thermal stresses or thermal strains may also be found out to first by finding out the amount of deformation due to change in temperature, and then by finding out thermal strain due to the deformation. The thermal stress may be found out the thermal strain. For such thermal stresses in tapering circular bars we are particularly interested in investigating the reliability by using the linear hazard model. It is also compared the results between the reliability of thermal stresses in bars if the ends of the bars are fixed to rigid supports and if the supports yield by an amount equal to $\Delta$.
\end{abstract}

Keywords - Thermal stresses, temperature, reliability, coefficient of linear expansion $(\alpha)$, time, linear hazard model.

\section{INTRODUCTION}

Whenever there is some rise or fall in the temperature of a body, the body will do some expansion or contraction due to the variation of temperature. A little consideration will show that, if the body expands or contract freely due to the rise or fall of the temperature, no stresses are induced on the body. But if the deformation of the body is constrained (i.e. restriction), then stresses are developed on the body reckoned as thermal stress or temperature stress. The corresponding strain is reckoned as thermal strain or temperature strain.

Reliability is used for developing the equipment manufacturing and delivery to the user. A reliable system is one which operates according to our expectations. Reliability of a system is the probability that a system perform its intended purpose for a given period of time under stated environment conditions. In some cases system failures occur due to certain type of stresses acting on them. These types of system are reckoned as stress dependent models of reliability. These models now a days studied in many branches of science such as Engineering (Manufacturing, Production), Medicine, Pharmaceutical industries, $\mathrm{R} \& \mathrm{D}$, and other various sectors, etc.

\author{
Ujjal Laha \\ Department of Mechanical Engineering, \\ Kanad Institute of Engineering and Management, \\ Mankar, W.B, India
}

In assessing system reliability it is first necessary to define and categorize different modes of system failures. It is difficult to define failure in unambiguous forms. However a system's performance can deteriorate gradually over time and sometimes there is only a fine line between systems success and system failure. Once the system function and failure modes are explicitly stated reliability can be precisely quantified by probability statements.

\section{METHODOLOGY (TACTICS)}

The probability of failure as a function of time can be defined $F(t)=(T \leq t)$, where $t \geq 0$

and $T$ is a random variable denoting the failure time.

The Reliability function can be defined as the probability of success for the intended time is

$R(t)=1-F(\mathrm{t})=P(T>t)$

The Hazard function $h(t)$ can be defined as the limit of the failure rate as the interval approaches to zero. Thus the hazard function is the instantaneous failure rates is defined as $\mathrm{z}(\mathrm{t})=\mathrm{f}(\mathrm{t}) / \mathrm{R}(\mathrm{t})=\mathrm{f}(\mathrm{t}) /\{1-\mathrm{F}(\mathrm{t})\}$ where $\mathrm{f}(\mathrm{t}) \mathrm{dt}=$ $\mathrm{dF}(\mathrm{t}) \ldots \ldots \ldots . . .(2.3)$;

$\mathrm{h}(\mathrm{t}) \quad \mathrm{z}(\mathrm{t}) \quad \mathrm{x}$

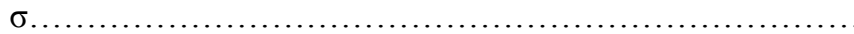

...(2.4);

when one kind of stress induced on the body.

\section{THERMAL STRESS IN CIRCULAR TAPERING SECTIONS:-}

a. Calculate the amount of deformation due to change of temperature with the assumptions that the bar is fixed at both ends.

b. Calculate the force (load) required to bring the deformed bar to the original length.

c. Calculate the stress and strain in the bar caused by the force.

Let

$1=$ length of the bar;

$\mathrm{d}_{1}=$ diameter of the larger end of the bar;

$\mathrm{d}_{2}=$ diameter of the smaller end of the bar;

$\theta=$ Increase of temperature;

$\alpha=$ Co-efficient of linear expansion. 
We know that as a result of the increase in temperature, the bar $\mathrm{AB}$ will tend to expand. But since it is fixed at both ends, therefore it will causes some compressive stress. We also know that increase in length due to rise of temperature. Therefore,

$\Delta \mathrm{l}$

$$
=1
$$

..(3.1);

Now let, $\mathrm{P}=$ load (or force) required to bring the deformed bar to the original length.

We know that decrease in the length of the circular bar due to load $\mathrm{P}$ is

$\Delta \mathrm{l}$

$(4 \times \mathrm{P} \times \mathrm{l}) /\left(\pi \times \mathrm{E} \times \mathrm{d}_{1} \times \mathrm{d}_{2}\right)$.

2);

Solving equation (3.1) and (3.2), we get-
1
$\times$
$\alpha$
$x$
$\theta$
$(4 \times \mathrm{P} \times 1) /\left(\pi \times \mathrm{E} \times \mathrm{d}_{1} \times \mathrm{d}_{2}\right)$....

Now,

$\mathrm{P}=$

$\left(\pi \times \mathrm{E} \times \mathrm{d}_{1} \times \mathrm{d}_{2} \times \alpha \times \theta\right) / 4$.

Maximum stress

$\left(\sigma_{\max }\right)=\mathrm{P} / \mathrm{A}=\mathrm{P} /\left(\pi / 4 \times \mathrm{d}_{2}^{2}\right)$

$=\left(\pi \times \mathrm{E} \times \mathrm{d}_{1} \times \mathrm{d}_{2} \times \alpha \times \theta\right) / 4 \times\left(\pi / 4 \times \mathrm{d}_{2}^{2}\right)$

$=\left(\begin{array}{llll}\alpha & \times & \theta & \times \mathrm{E}\end{array}\right.$

$\left.\mathrm{d}_{1}\right) / \mathrm{d}_{2}$

Table:-I- Value of Coefficient of linear expansion for the different materials body

\begin{tabular}{|c|l|l|}
\hline Serial Number & \multicolumn{1}{|c|}{ Material Body } & \multicolumn{1}{c|}{$\begin{array}{c}\text { Coefficient of linear } \\
\text { expansion( } \boldsymbol{\alpha} \text { ) }\end{array}$} \\
\hline 1 & Aluminium(Al) & $23 \times 10^{-6}$ to $24 \times 10^{-6}$ \\
\hline 2 & Steel & $\begin{array}{l}11.5 \times 10^{-6} \text { to } 13 \times \\
10^{-6}\end{array}$ \\
\hline 3 & $\begin{array}{l}\text { Cast iron, Wrought } \\
\text { iron }\end{array}$ & $11 \times 10^{-6}$ to $12 \times 10^{-6}$ \\
\hline 4 & Copper, Brass, Bronze & $17 \times 10^{-6}$ to $18 \times 10^{-6}$ \\
\hline
\end{tabular}

Table:-II-Value of Young's Modulus for the different materials body

\begin{tabular}{|c|c|c|}
\hline Serial Number & Material Body & $\begin{array}{c}\text { Modulus of } \\
\text { Elasticity (E) in GPa } \\
\left(\mathbf{K N} / \mathbf{m m}^{2}\right)\end{array}$ \\
\hline 1 & Aluminium & $60 \times 10^{3}$ to $80 \times 10^{3}$ \\
\hline 2 & Steel & $200 \times 10^{3}$ to $220 \times$ \\
\hline
\end{tabular}

\begin{tabular}{|c|l|l|}
\hline & & $10^{3}$ \\
\hline 3 & Cast Iron & $\begin{array}{l}100 \times 10^{3} \text { to } 160 \times \\
10^{3}\end{array}$ \\
\hline 4 & Wrought Iron & $\begin{array}{l}190 \times 10^{3} \text { to } 200 \times \\
10^{3}\end{array}$ \\
\hline 5 & & $90 \times 10^{3}$ to $110 \times 10^{3}$ \\
\hline 6 & Copper & $8010^{3}$ to $90 \times$ \\
& Brass & $10^{3}$ \\
\hline
\end{tabular}

\section{LINEARLY INCREASING HAZARD} MODEL:

When there is wear or deterioration of parts or components, the failure rate increases with time. The simplest model that we can consider in this category is one in which the Failure Rate increases linearly with time.

Let

$\mathrm{z}(\mathrm{t})=\mathrm{kt}$

(4.1);

where $\mathrm{k}$ is a constant

Therefore, $\mathrm{h}(\mathrm{t})=\mathrm{z}(\mathrm{t}) \times \sigma \quad=\mathrm{kt} \times$ $\sigma \ldots \ldots \ldots \ldots \ldots \ldots \ldots \ldots \ldots \ldots \ldots \ldots . . . .(4.2)$

When $\sigma_{\max }=$ MAXIMUM STRESS IN THE TAPERING CIRCULAR BAR IF THE ENDS OF THE BAR ARE FIXED TO RIGID SUPPORTS:

Stress in the bar $\left(\sigma_{\max }\right)=\left(\alpha \times \theta \times \mathrm{E} \times \mathrm{d}_{1}\right) / \mathrm{d}_{2}$ (from, equation $3,5)$

Therefore, Reliablity of the bar R(t)

$=\quad \exp \left[-\quad\left(\mathrm{K} \times \alpha \times \times \theta \times \mathrm{d}_{1} \times \mathrm{t}^{2}\right) /\left(2 \mathrm{~d}_{2}\right)\right.$

Illustration-1:- A circular bar rigidly fixed at its ends which is $1.2 \mathrm{~m}$ long. It uniformly tapers from $100 \mathrm{~mm}$ at one end to $75 \mathrm{~mm}$ at the other end. What is the maximum stress induced in the bar, when its temperature raised through $25 \mathrm{~K}$. Take E as $200 \mathrm{GPa}$ and $\alpha=12 \times 10^{-6} / \mathrm{K}$. Also, find the reliability of the bar for linear hazard model.

\section{Solution-1:}

Diameter at larger end $\left(\mathrm{d}_{1}\right)=100 \mathrm{~mm}$;

Diameter at smaller end $\left(\mathrm{D}_{2}\right)=75 \mathrm{~mm}$;

Rise in temperature $(\theta)=25 \mathrm{~K}$;

$\mathrm{E}=200 \times 10^{3} \mathrm{~N} / \mathrm{mm}^{2}$;

$\alpha=12 \times 10^{-6} / \mathrm{k}$.

We know that the maximum stress developed in the bar,

$\sigma_{\max }=\left(\alpha \times \theta \times \mathrm{E} \times \mathrm{d}_{1}\right) / \mathrm{d}_{2}$

Putting the values of the above equation, we get maximum stress $=80 \mathrm{~N} / \mathrm{mm}^{2}=80 \mathrm{MPa}$

Reliability of the Bar R(t)

$=\exp \left[-\left(\mathrm{K} \times \alpha \times \times \theta \times \mathrm{d}_{1} \times \mathrm{t}^{2}\right) /\left(2 \mathrm{~d}_{2}\right)\right.$ 
$=\exp \left[-(0.01) \times 80 \times 0.1^{2} / 2\right]$

$$
=0.99996
$$

WHEN $\sigma_{\max }=$ MAXIMUM STRESS IN THE TAPERING CIRCULAR BAR IF THE SUPPORTS YIELD BY AN AMOUNT EQUAL TO $\triangle$ :

If the supports yield by an amount equal to $\delta$, then the actual expansion that has taken place,

$\Delta \mathrm{l}=(1 \times \alpha \times \mathrm{t})-\delta$.

Now let, $\mathrm{P}=$ load (or force) required to bring the deformed bar to the original length.

We know that decrease in the length of the circular bar due to load $\mathrm{P}$ is -

$\Delta \mathrm{l}$

$$
\left(\pi \times \mathrm{E} \times \mathrm{d}_{1} \times \mathrm{d}_{2} \times \alpha \times \theta\right) / 4
$$

Solving equation (2.5) and (2.6), we get-
$(1$$$
\alpha
$$
$\theta)$ $(4.5)$
$(4 \times \mathrm{P} \times 1) /\left(\pi \times \mathrm{E} \times \mathrm{d}_{1} \times \mathrm{d}_{2}\right)$

From 4.5 , we get the formula of $P$, i.e.

$\mathrm{P} \quad=\quad \begin{array}{lllllll}\mathrm{Ed}_{1} & \mathrm{~d}_{2} & (1 & \times & \alpha & \times & \theta\end{array}$

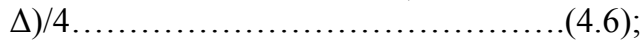

Now, Maximum stress
$\left(\sigma_{\max }\right)=$
$(1$
$(47)$;
D) $\quad \mathrm{Ed}_{1} / \mathrm{d}_{2}$

Therefore, Reliability of the Bar R(t)
$=\quad \exp [-\mathrm{K}$
$(1$
$\alpha$

Illustration-2:- A circular bar rigidly fixed at its ends which is $1.2 \mathrm{~m}$ long. It uniformly tapers from $100 \mathrm{~mm}$ at one end to $75 \mathrm{~mm}$ at the other end. What is the maximum stress induced in the bar, when its temperature raised through $25 \mathrm{~K}$, if the ends yield by $0.3 \mathrm{~mm}$. Take $\mathrm{E}$ as $200 \mathrm{GPa}$ and $\alpha=12 \times$ $10^{-6} / \mathrm{K}$. Also, find the reliability of the bar for linear hazard model.

\section{Solution-2:}

Diameter at larger end $\left(\mathrm{d}_{1}\right)=100 \mathrm{~mm}$;

Diameter at smaller end $\left(\mathrm{D}_{2}\right)=75 \mathrm{~mm}$;

Rise in temperature $(\theta)=25 \mathrm{~K}$;

$\mathrm{E}=200 \times 10^{3} \mathrm{~N} / \mathrm{mm}^{2}$;

$\alpha=12 \times 10^{-6} / \mathrm{k}$.

We know that the maximum stress developed in the bar,

$\sigma_{\max }=(1 \times \alpha \times \theta-\Delta) \operatorname{Ed}_{1} / d_{2}$

$=16 \mathrm{KN} / \mathrm{mm}^{2}$

Reliability of the Bar R(t)

$=\exp \left[-\mathrm{K}(1 \times \alpha \times \theta-\Delta) E \times \mathrm{d}_{1} \times \mathrm{t}^{2} / 2 \mathrm{~d}_{2}\right.$

$=\exp [-(0.01) \times 16000]$

$=\exp [-0.008]$

$=0.99203$

\section{Graphical Representation of Reliability with the computation of Steel Tapering Circular Bar:}

Reliability Computation of Tapering Circular Bar when $\boldsymbol{\sigma}=$ Stress in the rod if the ends do not yield when $\mathrm{t}=0.01$ and $\alpha=12 \times 10^{-6} / \mathrm{k}$ :

\section{Table-III}

\begin{tabular}{|c|c|c|l|c|}
\hline Constant(k) & $\begin{array}{c}\text { Temperature } \\
\boldsymbol{\theta}\left({ }^{\circ} \mathbf{K}\right)\end{array}$ & $\begin{array}{c}\text { Modulus of } \\
\text { Elasticity(E) }\end{array}$ & Stress(\%) & $\mathbf{R}(\mathbf{t})$ \\
\hline 0.01 & 25 & $200 \mathrm{GPa}$ & $80 \mathrm{MPa}$ & 0.99960 \\
\hline 0.02 & 25 & $200 \mathrm{GPa}$ & $80 \mathrm{MPa}$ & 0.99920 \\
\hline 0.03 & 25 & $200 \mathrm{GPa}$ & $80 \mathrm{MPa}$ & 0.99880 \\
\hline 0.04 & 25 & $200 \mathrm{GPa}$ & $80 \mathrm{MPa}$ & 0.99840 \\
\hline 0.05 & 25 & $200 \mathrm{GPa}$ & $80 \mathrm{MPa}$ & 0.99810 \\
\hline 0.06 & 25 & $200 \mathrm{GPa}$ & $80 \mathrm{MPa}$ & 0.99760 \\
\hline 0.07 & 25 & $200 \mathrm{GPa}$ & $80 \mathrm{MPa}$ & 0.99720 \\
\hline 0.08 & 25 & $200 \mathrm{GPa}$ & $80 \mathrm{MPa}$ & 0.99680 \\
\hline 0.09 & 25 & $200 \mathrm{GPa}$ & $80 \mathrm{MPa}$ & 0.99640 \\
\hline 0.10 & 25 & $200 \mathrm{GPa}$ & $80 \mathrm{MPa}$ & 0.99600 \\
\hline
\end{tabular}

Graph- I

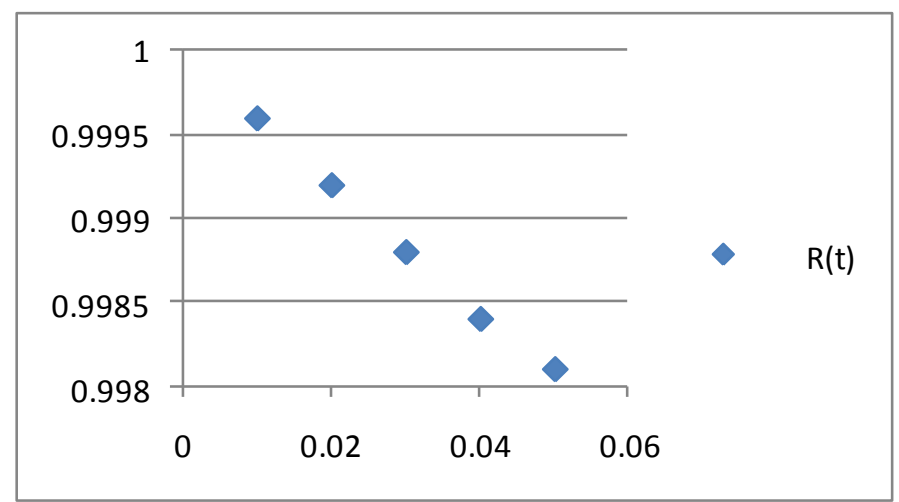

Reliability Computation of Tapering Circular Bar when $\boldsymbol{\sigma}=$ Stress in the rod if the ends do not yield when $\mathrm{k}=0.01$ and $\alpha=12 \times 10^{-6} / \mathrm{k}$ :

\begin{tabular}{|c|c|c|c|c|}
\hline Time(t) & $\begin{array}{l}\text { Temperature } \\
\theta\left({ }^{\circ} \mathbf{K}\right)\end{array}$ & $\begin{array}{l}\text { Modulus of } \\
\text { Elasticity(E) }\end{array}$ & $\operatorname{Stress}(\sigma)$ & $\mathbf{R}(\mathbf{t})$ \\
\hline 0.01 & 25 & $200 \mathrm{GPa}$ & $80 \mathrm{MPa}$ & 0.99960 \\
\hline 0.02 & 25 & $200 \mathrm{GPa}$ & $80 \mathrm{MPa}$ & 0.99840 \\
\hline
\end{tabular}

Table-IV 
International Journal of Engineering Applied Sciences and Technology, 2019

Vol. 4, Issue 4, ISSN No. 2455-2143, Pages 136-140

Published Online August 2019 in IJEAST (http://www.ijeast.com)

\begin{tabular}{|l|c|c|l|l|}
\hline 0.03 & 25 & $200 \mathrm{GPa}$ & $80 \mathrm{MPa}$ & 0.99640 \\
\hline 0.04 & 25 & $200 \mathrm{GPa}$ & $80 \mathrm{MPa}$ & 0.99362 \\
\hline 0.05 & 25 & $200 \mathrm{GPa}$ & $80 \mathrm{MPa}$ & 0.99219 \\
\hline 0.06 & 25 & $200 \mathrm{GPa}$ & $80 \mathrm{MPa}$ & 0.86588 \\
\hline 0.07 & 25 & $200 \mathrm{GPa}$ & $80 \mathrm{MPa}$ & 0.82201 \\
\hline 0.08 & 25 & $200 \mathrm{GPa}$ & $80 \mathrm{MPa}$ & 0.77414 \\
\hline 0.09 & 25 & $200 \mathrm{GPa}$ & $80 \mathrm{MPa}$ & 0.72325 \\
\hline 0.10 & 25 & $200 \mathrm{GPa}$ & $80 \mathrm{MPa}$ & 0.99600 \\
\hline
\end{tabular}

\begin{tabular}{|c|c|c|c|c|}
\hline 0.07 & 25 & $200 \mathrm{GPa}$ & $16 \mathrm{GPa}$ & 0.94553 \\
\hline 0.08 & 25 & $200 \mathrm{GPa}$ & $16 \mathrm{GPa}$ & 0.93810 \\
\hline 0.09 & 25 & $200 \mathrm{GPa}$ & $16 \mathrm{GPa}$ & 0.93053 \\
\hline 0.10 & 25 & $200 \mathrm{GPa}$ & $16 \mathrm{GPa}$ & 0.92311 \\
\hline
\end{tabular}

\section{Graph-III}

\section{Graph-II}

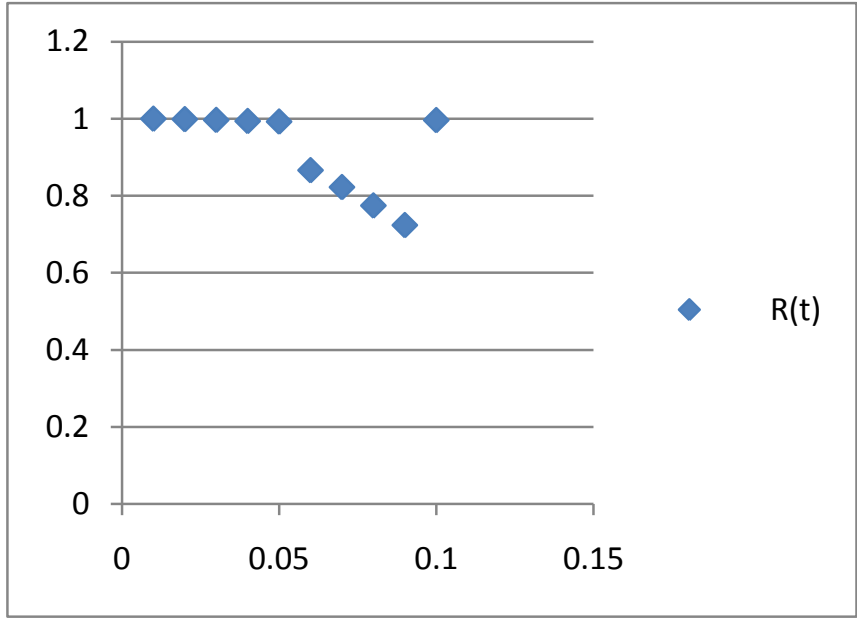

Reliability Computation of Tapering Circular Bar when $\sigma=$ Stress in the rod if the ends yields by an amount $\Delta=0.3 \mathrm{~mm}$ when $\mathrm{t}=0.01$ and $\alpha=12 \times 10^{-}$ $6 / \mathrm{k}$ :

\section{Table-V}

\begin{tabular}{|c|c|r|r|l|}
\hline Constant(k) & $\begin{array}{l}\text { Temperat } \\
\text { ure } \boldsymbol{\theta}\left({ }^{\circ} \mathbf{K}\right)\end{array}$ & $\begin{array}{l}\text { Modulus of } \\
\text { Elasticity(E) }\end{array}$ & Stress( $\boldsymbol{\sigma})$ & $\mathbf{R}(\mathbf{t})$ \\
\hline 0.01 & 25 & $200 \mathrm{GPa}$ & $16 \mathrm{GPa}$ & 0.99203 \\
\hline 0.02 & 25 & $200 \mathrm{GPa}$ & $16 \mathrm{GPa}$ & 0.98412 \\
\hline 0.03 & 25 & $200 \mathrm{GPa}$ & $16 \mathrm{GPa}$ & 0.97628 \\
\hline 0.04 & 25 & $200 \mathrm{GPa}$ & $16 \mathrm{GPa}$ & 0.96850 \\
\hline 0.05 & 25 & $200 \mathrm{GPa}$ & $16 \mathrm{GPa}$ & 0.96078 \\
\hline 0.06 & 25 & $200 \mathrm{GPa}$ & $16 \mathrm{GPa}$ & 0.95313 \\
\hline
\end{tabular}

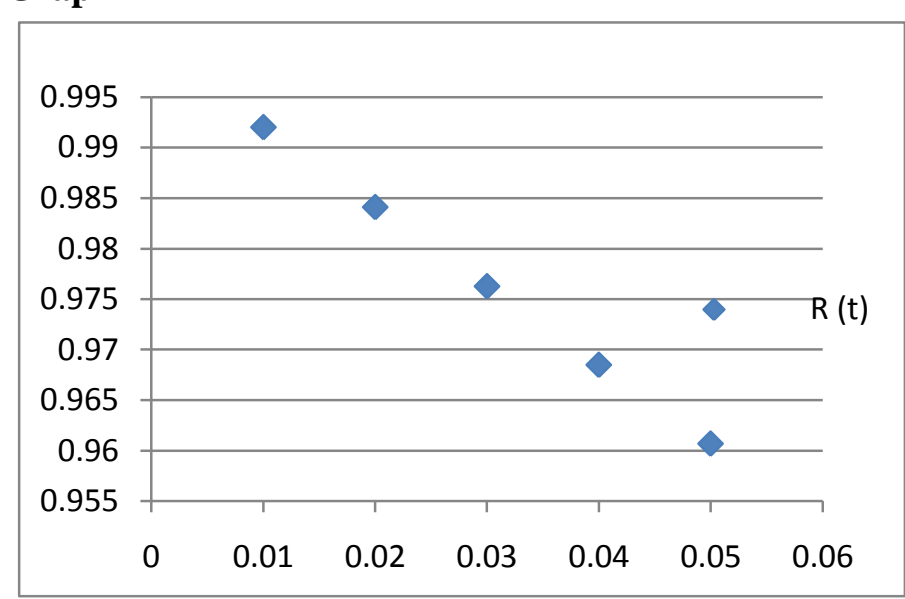

Reliability Computation of Tapering Circular Bar when $\boldsymbol{\sigma}=$ Stress in the rod if the ends yields by an amount $\Delta=0.3 \mathrm{~mm}$ when $\mathrm{K}=0.01$ and $\alpha=12 \times 10^{-}$ $6 / \mathrm{k}$ :

\section{Table-VI}

\begin{tabular}{|c|c|c|c|c|}
\hline Time(t) & $\begin{array}{l}\text { Temperature } \\
\boldsymbol{\theta}\left({ }^{\circ} \mathbf{K}\right)\end{array}$ & $\begin{array}{l}\text { Modulus of } \\
\text { Elasticity(E) }\end{array}$ & $\operatorname{Stress}(\sigma)$ & $\mathbf{R}(\mathbf{t})$ \\
\hline 0.01 & 25 & $200 \mathrm{GPa}$ & $16 \mathrm{GPa}$ & 0.99203 \\
\hline 0.02 & 25 & $200 \mathrm{GPa}$ & $16 \mathrm{GPa}$ & 0.96850 \\
\hline 0.03 & 25 & $200 \mathrm{GPa}$ & $16 \mathrm{GPa}$ & 0.93053 \\
\hline 0.04 & 25 & $200 \mathrm{GPa}$ & $16 \mathrm{GPa}$ & 0.87985 \\
\hline 0.05 & 25 & $200 \mathrm{GPa}$ & $16 \mathrm{GPa}$ & 0.81873 \\
\hline 0.06 & 25 & $200 \mathrm{GPa}$ & $16 \mathrm{GPa}$ & 0.74976 \\
\hline 0.07 & 25 & $200 \mathrm{GPa}$ & $16 \mathrm{GPa}$ & 0.67570 \\
\hline 0.08 & 25 & $200 \mathrm{GPa}$ & $16 \mathrm{GPa}$ & 0.59929 \\
\hline 0.09 & 25 & $200 \mathrm{GPa}$ & $16 \mathrm{GPa}$ & 0.52309 \\
\hline 0.10 & 25 & $200 \mathrm{GPa}$ & $16 \mathrm{GPa}$ & 0.44932 \\
\hline
\end{tabular}




\section{Graph- IV}

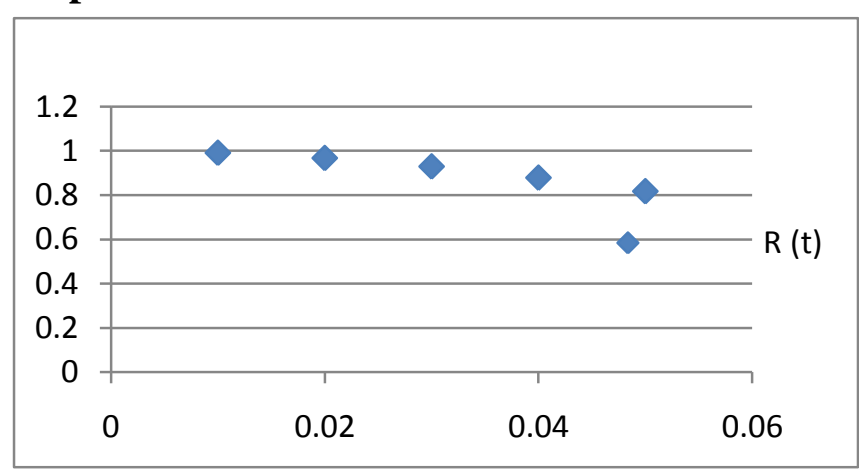

V. CONCLUSION:-

Reliability of the thermal stresses or the thermal strains are set up initially by finding out the amount of deformation due to the change in temperature. Reliability calculations are obtained for the tapering circular bars when stress $(\sigma)$ in the Rod (a) if the ends do not yield and (b) if the ends yield by an equal to amount $\Delta$ for various materials. Now as per the observation, when temperature remains constant, reliability decreases when constant term (k) increases. Similarly, temperature remains constant, but reliability decreases when time increases linearly. It is observed that the reliability is always depended on the coefficient of linear expansion. Therefore, the reliability varies with the certain parameters as well as the coefficient of linear expansion.

\section{REFERENCES:}

1. Cetkin. E, Lorente. S and Bejan. A et al (2014) in their work, "Vascularization for Cooling and Reduced Thermal Stresses", in International Journal of Heat and Mass Transfer, Elsevier, (pp. 858-864).

2. Chauthale. S and Khobragade. N.W et al (2017) in their work, "Three Dimensional Thermal Stress Analysis of Rectangular Plate Using Integral Transform Method", in Global Journal of Pure and Applied Mathematics, (pp. 7479-7504).

3. Parit A.N, Tadamalle A.P and Ramaswamey. V et al (2014) in their work, "Thermal Stress and Creep Analysis of Failed Tube of Secondary Super Heater", $5^{\text {th }}$ International \& $26^{\text {th }}$ All India Manufacturing Technology, Design and Research Conference (AIMTDR 2014), IIT Guwahati, Assam, India, (pp. 207-1 to 207-6).

4. Hari Prasad. P and Uma Maheswari. T et al (2013) in their work, "Reliability of Thermal Stresses in Bars When Stress Follows Half-Logistic Distribution", in International Journal of Computational Engineering Research, (pp. 43-46).
5. Srivatsava. S, Sekhar. A, Sundaram N.S , Kumar.S.S and Hariharan V.K in their work, "Modular Design of Mechanical Handling System for Spacecraft's Integration on Ground", in ISME Journal of Mechanics and Design, (pp. 01-08).

6. Shang T.Y, Qian Qi , Long Y.P and Zhang .G et al (2019) in their work, "Mechanical Behaviour Analysis of Hollow Thrust Tapered Roller Bearing" in International Journal of Engineering Applied Sciences and Technology, (pp. 05-09).

7. Hari Prasad. P and Uma Maheswari. T et al (2013) in their work, "Reliability of Thermal Strain and Stresses in Simple Bars", in IOSR Journal of Mathematics, (pp. 0509).

8. Manikrao Athawale. V and Chakraborty. S et al (2010) in their work, " A TOPSIS method-based Approach to Machine Tool Selection" in International Conference on Industrial Engineering and Operations Management, Dhaka, Bangladesh, (pp. 01-06).

9. Dr. Hemachandra Reddy. K and Dr. Naga Malleshwara Rao. G et al (2013) in their work, "Analysis of Thermal Stresses in Heat Exchanger to Find Optimum Wall Thickness Through ANSYS" in International Journal of Innovative Research in Science, Engineering and Technology, (pp. 01-06).

10. Cetkin. E, Lorente. S and Bejan. A et al (2011) in their work, "Vascularization for Cooling and Mechanical Strength", in International Journal of Heat and Mass Transfer, Elsevier, (pp. 2774-2781).

11. Rakshit. A et al (2018) in their work, "Conception on One-Way ANOVA Technique with the assist of Illustration", in International Journal of Innovative Research in Technology, (pp. 88 -92).

12. Rakshit. A, Ghosh. S and Chatterjee. S et al (2019) in their work, "Two Way Analysis of Variance: The Fundamental Concepts with the Aid of Applications", in International Journal of Innovative Science, Engineering and Technology, (pp. 06 - 14). 